\title{
Correlation between radiographically diagnosed osteophytes and magnetic resonance detected cartilage defects in the tibiofemoral joint
}

\author{
Torsten Boegård, Olof Rudling, Ingemar F Petersson, Kjell Jonsson
}

\begin{abstract}
Objective-To assess the correlation between the presence of radiographically diagnosed osteophytes in the tibiofemoral joint (TFJ) and (1) magnetic resonance (MR) detected cartilage defects and meniscal lesions in the same joint and (2) knee pain.

Methods-Fifty nine people, 29 men and 30 women, with chronic knee pain (aged 41-58 years, mean 50 years) were examined with posteroanterior weightbearing radiograms in semiflexion of both TFJ. The presence and grade of marginal and central osteophytes were assessed. On the same day, an MR examination was performed of the signal knee with proton density and $T 2$ weighted turbo spin-echo sequences on a 1.0 T imager. Cartilage defects and meniscal abnormalities in the TFJ were noted. The subjects were questioned for current knee pain for each knee. Results-Marginal osteophytes had a sensitivity of $77 \%$, specificity of $83 \%$, and positive predictive value of $87 \%$ for $M R$ detected cartilage defects in the TFJ and a sensitivity of $71 \%$, specificity of $68 \%$, and positive predictive value of $71 \%$ for meniscal abnormalities. A correlation $(p<0.05)$ between osteophytes at the medial tibial condyle and knee pain was found.

Conclusions-With the presence of marginal osteophytes in the TFJ there is a high prevalence of MR detected cartilage defects in the same joint whether joint space narrowing $(<3 \mathrm{~mm})$ is present or not. (Ann Rheum Dis 1998;57:401-407)
\end{abstract}

Department of
Diagnostic Radiology, County Hospital,

Helsingborg, Sweden

T Boegård

O Rudling

Department of Diagnostic Radiology, University Hospital, Lund, Sweden

K Jonsson

Spenshult's Hospital for Rheumatic

Diseases, Halmstad, Sweden

I F Petersson

Correspondence to:

Dr T Boegård, Department of Diagnostic Radiology,

County Hospital, S-251 87

Helsingborg, Sweden.

Accepted for publication 8 April 1998

Osteoarthritis (OA) is a multifactorial process affecting cartilage and subchondral bone in synovial joints. The presence of osteophytes

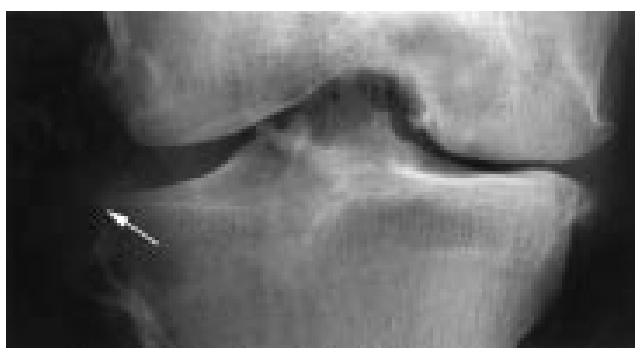

Figure 1 A 57 year old woman with a posteroanterior radiogram of the right knee demonstrating a marginal osteophyte grade 2 at the medial tibial condyle and an osteophyte grade 1 at the medial femoral condyle and at the lateral tibial condyle (arrow). The joint space width is $1 \mathrm{~mm}$ medially and $5 \mathrm{~mm}$ laterally. has been regarded as an early sign of OA in the tibiofemoral joint (TFJ) since Kellgren and Lawrence developed a grading system in $1957 .{ }^{1}$ The classification was based on anteroposterior radiograms in supine position and was published in an atlas. ${ }^{2}$ In this system the presence of doubtful and definite osteophytes was defined as the first and second grade of OA respectively and moderate joint space narrow-
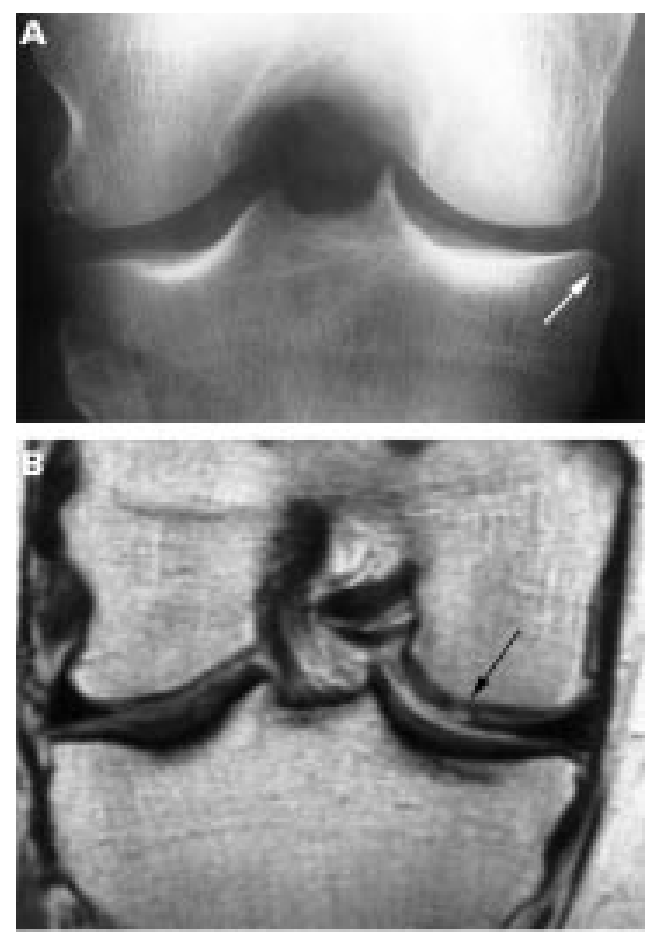

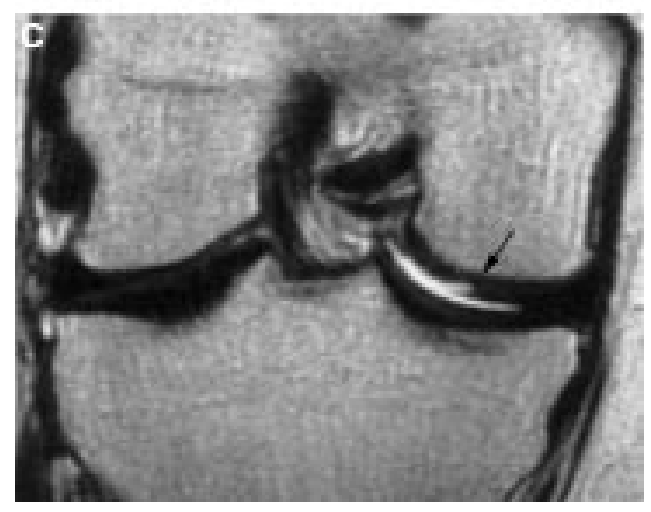

Figure 2 A 57 year old woman with $(A)$ a posteroanterior radiogram of the right knee showing normal joint space width medially $(4 \mathrm{~mm})$ and laterally $(5 \mathrm{~mm})$. At the medial tibial condyle there is a marginal osteophyte grade 1 (arrow). In the corresponding (B) Pd and (C) T2 weighted coronal MR images, a cartilage defect grade 2 in the medial femoral condyle is shown (arrow). 
Figure $3 A 42$ year old man with $(A)$ a posteroanterior radiogram of the right knee, demonstrating normal joint space width medially (6 $\mathrm{mm}$ ) and laterally $(5 \mathrm{~mm})$. (B) $A$ close up of the lateral compartment to show a marginal osteophyte grade 1 at the tibial and femoral condyles. In the corresponding $(C)$ sagittal $P d$ weighted MR image of the lateral compartment is demonstrated cartilage defects grade 2 at the femoral and tibial condyles (arrows). Note the truncation of the posterior portion of the lateral meniscus.
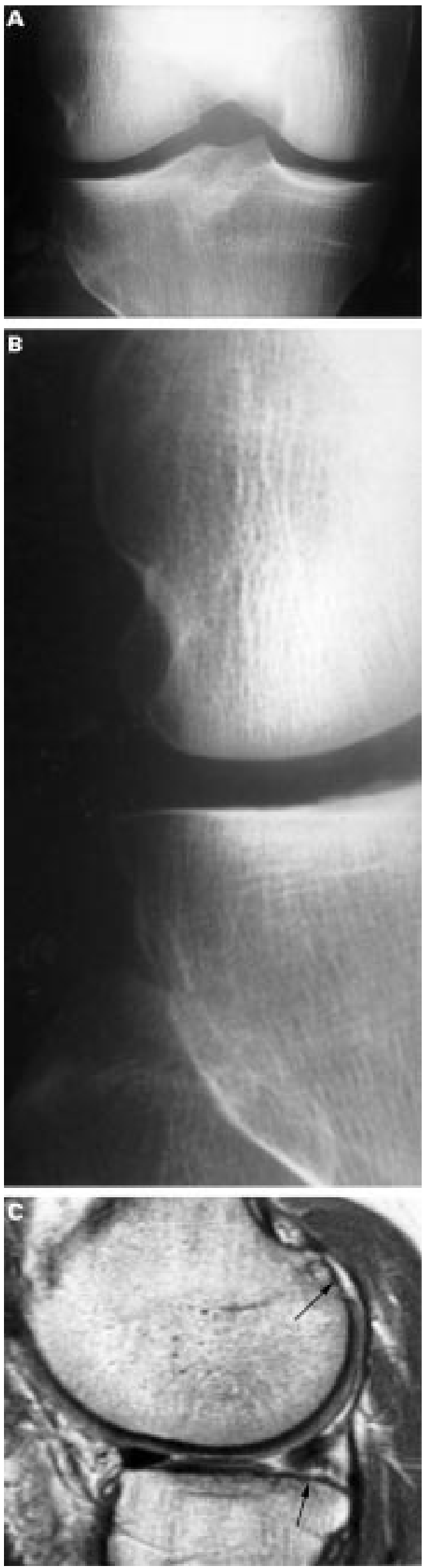

ing as the third grade. In the original definition the presence of osteophytes was not included in the third grade.

In 1968 Ahlbäck $^{3}$ introduced examination of the knee with weightbearing, which demonstrated joint space narrowing of the TFJ more accurately than examination in supine position. $\mathrm{He}$ also created a classification for OA, based on the presence of narrowing or obliteration of the joint space and bone loss.

In recent years several investigators have found a stronger association between knee pain and osteophytes than between knee pain and joint space narrowing. ${ }^{4-6}$ These results have been reported for the tibiofemoral as well as for the patellofemoral joint. It has been suggested that OA should be diagnosed by the presence of osteophytes and its severity and progression by joint space narrowing. ${ }^{7}$

MR imaging with its good tissue contrast and anatomical resolution ${ }^{8}$ provides a noninvasive examination tool of the TFJ in early stages of OA, for detection of cartilage defects.

The aim of our study was to assess the correlation between the presence of osteophytes in posteroanterior weightbearing radiograms with semiflexion and fluoroscopic guidance of the TFJ and (1) MR detected cartilage defects and meniscal lesions in the same joint and (2) knee pain.

\section{Methods}

SUBJECTS

To create a cohort of people with chronic knee pain (duration $>3$ months at inclusion) for prospective follow up, an epidemiological survey of 2000 people aged $35-54$ years in a rural area in southern Sweden, was performed. ${ }^{9}$ Chronic knee pain was reported by 279 of 2000 and 204 of 279 accepted to be examined clinically, biochemically, and radiographically at baseline 1990-91. At the three year follow up a subgroup of 61 were chosen as a random sample from the initial cohort of 204, after exclusion of those with joint disorders other than OA and those having OA with obliteration of the joint space or bone attrition. All 61 subjects had a posteroanterior radiogram of both TFJ. MR imaging of the signal knee (the most painful at inclusion) was performed in 60 of 61 patients. One patient could not take part in the MR study because of claustrophobia. The MR examination was diagnostic in all except one patient (59 of 60) because of trembling caused by Parkinson's disease. Thus 59 of 61 patients were included in the study. There were 30 women (aged 42-58, mean 50.7) and 29 men (aged 41-57, mean 49.5). Both examinations in each patient were performed on the same day.

\section{KNEE PAIN}

At follow up the subjects were questioned for current knee pain for each knee. The difference in the number of osteophytes between the signal knee and the contralateral knee was calculated in patients who had or had had pain (at inclusion in the study) in the signal knee only. 
Table 1

(A) The number (\%) and grade of radiographic osteophytes in the TFF of the signal knees

\begin{tabular}{lllllll}
\hline Grade & Medial femur & Lateral femur & Medial tibia & Lateral tibia & Tibial spine & Intercondylar \\
\hline 0 & $47(80)$ & $54(92)$ & $29(49)$ & $45(76)$ & $24(41)$ & $35(61)$ \\
1 & $8(14)$ & $4(7)$ & $25(42)$ & $12(20)$ & $34(59)$ & $22(39)$ \\
2 & $3(5)$ & $1(2)$ & $5(8)$ & $2(3)$ & & 57 \\
3 & $1(2)$ & 59 & 59 & 59 & 58 & 57
\end{tabular}

\begin{tabular}{|c|c|c|c|c|c|c|}
\hline Grade & Medial femur & Lateral femur & Medial tibia & Lateral tibia & Tibial spine & Intercondylar \\
\hline $\begin{array}{l}0 \\
1\end{array}$ & $\begin{array}{c}55(93) \\
4(7)\end{array}$ & $59(100)$ & $\begin{array}{l}38(64) \\
21(36)\end{array}$ & $\begin{array}{r}52(88) \\
7(12)\end{array}$ & $\begin{array}{l}19(33) \\
38(67)\end{array}$ & $\begin{array}{l}32(56) \\
25(44)\end{array}$ \\
\hline Total & 59 & 59 & 59 & 59 & 57 & 57 \\
\hline
\end{tabular}

RADIOGRAPHIC EXAMINATION

Radiograms in posteroanterior view of both TFJ were obtained in the weightbearing position and in semiflexion with fluoroscopic guidance on a tiltable table with a spotfilm device and with a tube angulation possibility. ${ }^{10}$ The radiograms were obtained with almost the whole weight on the examined leg and with the patella touching the table. The knee was flexed $30-50^{\circ}$ and the medial aspect of the foot was parallel to the central $x$ ray beam and the beam was adjusted to be tangential to the anterior and posterior aspect of the medial tibial condyle. The film focus distance was $115 \mathrm{~cm}$. The radiograms were evaluated for osteophytes at the medial and lateral tibial and femoral condyles (defined as marginal osteopyhtes) into four grades (0-3) according to a radiographic atlas published by Altman et al. ${ }^{11}$ Figure 1 shows osteophytes of grade 1 and 2 . Osteophytes at the tibial eminence and adjacent to the intercondylar fossa in the femur (defined as central osteophytes) were registered as present or absent. Marginal osteophytes were correlated to the minimal joint space width - that is, narrowing $(<3 \mathrm{~mm})$ and

Table 2

(A) Presence of marginal osteophytes in the medial TF compartment

\begin{tabular}{|c|c|c|c|}
\hline & $\begin{array}{l}\text { Osteophyte medial } \\
\text { tibia }\end{array}$ & $\begin{array}{l}\text { No osteophyte medial } \\
\text { tibia }\end{array}$ & Total \\
\hline Osteophyte medial femur & 12 & 0 & 12 \\
\hline No osteophyte medial femur & 18 & 29 & 47 \\
\hline Total & 30 & 29 & 59 \\
\hline \multicolumn{4}{|c|}{ (B) Presence of marginal osteophytes in the lateral TF compartment } \\
\hline & $\begin{array}{l}\text { Osteophyte lateral } \\
\text { tibia }\end{array}$ & $\begin{array}{l}\text { No osteophyte lateral } \\
\text { tibia }\end{array}$ & Total \\
\hline Osteophyte lateral femur & 5 & 0 & 5 \\
\hline No osteophyte lateral femur & 9 & 45 & 54 \\
\hline Total & 14 & 45 & 59 \\
\hline
\end{tabular}

Table 3 Number and grade of marginal osteophytes at the medial tibial and medial femoral condyles in the signal knee in 59 subjects. (MFS = minimum joint space)

\begin{tabular}{lcccccccc}
\hline $\begin{array}{l}\text { MFS } \\
(\mathrm{mm})\end{array}$ & $\begin{array}{l}\text { Grade 0 } \\
\text { tibia }\end{array}$ & $\begin{array}{l}\text { Grade 0 } \\
\text { femur }\end{array}$ & $\begin{array}{l}\text { Grade 1 } \\
\text { tibia }\end{array}$ & $\begin{array}{l}\text { Grade 1 } \\
\text { femur }\end{array}$ & $\begin{array}{l}\text { Grade 2 } \\
\text { tibia }\end{array}$ & $\begin{array}{l}\text { Grade 2 } \\
\text { femur }\end{array}$ & $\begin{array}{l}\text { Grade 3 } \\
\text { tibia }\end{array}$ & $\begin{array}{l}\text { Grade 3 } \\
\text { femur }\end{array}$ \\
\hline 8 & 1 & 1 & - & - & - & - & - & - \\
7 & - & 1 & 1 & - & - & - & - & - \\
6 & 1 & 5 & 4 & - & - & - & - & - \\
5 & 10 & 14 & 5 & 1 & - & - & - & - \\
4 & 12 & 18 & 6 & - & - & - & - & - \\
3 & 4 & 8 & 7 & 3 & 1 & 1 & - & - \\
2 & - & - & 1 & 1 & - & - & - & - \\
1 & - & - & 2 & 2 & 1 & 1 & - & 1 \\
0 & - & - & - & 1 & 3 & 1 & - & \\
Total & 28 & 47 & 26 & 8 & 5 & 3 & 0 & \\
\hline
\end{tabular}

non-narrowing $(\geqslant 3 \mathrm{~mm})$. The joint space width measurements in the patients studied were reproducible and have been reported in a previous study. ${ }^{10}$ The minimal joint space width in the TFJ was measured in $\mathrm{mm}$ with a standard plastic $\mathrm{mm}$ ruler on the plain film across the narrowest part of the joint space in both the medial and lateral compartment. The bony margins used for measuring the interbone distance in our study have been described by Buckland-Wright. ${ }^{12}$

All radiograms were evaluated by one observer (TB 1). The films of the signal knees were read once more by the same observer (TB 2) and once by another observer (OR) for calculating the $\kappa$ values for intraobserver and interobserver variation and the percentage concordance within and between the observers. The radiograms were assessed without knowledge of the name and age of the subjects, or the results from previous examinations.

\section{MR EXAMINATION}

MR imaging was performed in the signal knee with a $1.0 \mathrm{~T}$ imager (Impact, Siemens) with a circular polarised surface coil. The first seven patients were examined with a coronal T1 weighted spin-echo sequence, a sagittal proton density and T2 weighted turbo spin-echo sequence (tSEPdT2) and a $3 \mathrm{D}$ gradient echo sequence (Dess). The remaining patients were examined with tSEPdT2 in the coronal, sagittal, and axial views. The sagittal sequence was perpendicular to a line connecting the dorsal aspects of the femoral condyles, the coronal sequence was parallel to that line and the axial sequence was perpendicular to the long axis of the patella. The sequence parameters for the tSEPdT2 were: TR/TE 4200/15-105 ms with two signals averaged, echo train length 7 , FOV $145 \times 145 \mathrm{~mm}$, section thickness $3 \mathrm{~mm}$ with $0.3-0.6 \mathrm{~mm}$ intersection gap, matrix size $252 \times$ 256, and acquisition time $5 \min 8 \mathrm{~s}$.

The MR examinations were assessed for cartilage defects in each of the articular surfaces of the TFJ. ${ }^{10}$ The defects were graded: as absent (grade 0 ); as $\leqslant 50 \%$ reduction of the cartilage thickness (grade 1); as $>50 \%$ reduction of the cartilage thickness (grade 2); and as involving bone loss (grade 3). Signal changes in the cartilage with an intact surface were not registered. Figure 2 shows a posteroanterior radiogram with a marginal osteophyte and 
Table 4 Number (\%) and grade of $M R$ detected cartilage defects of the TFF in 59 subjects

\begin{tabular}{lcccc}
\hline $\begin{array}{l}\text { MR } \\
\text { grade }\end{array}$ & $\begin{array}{l}\text { Medial } \\
\text { femur }\end{array}$ & $\begin{array}{l}\text { Medial } \\
\text { tibia }\end{array}$ & $\begin{array}{l}\text { Lateral } \\
\text { femur }\end{array}$ & $\begin{array}{l}\text { Lateral } \\
\text { tibia }\end{array}$ \\
\hline 0 & $34(58)$ & $47(80)$ & $48(81)$ & $50(85)$ \\
1 & $6(10)$ & $2(3)$ & $4(7)$ & $3(5)$ \\
2 & $15(25)$ & $7(12)$ & $5(8)$ & $5(8)$ \\
3 & $4(7)$ & $3(5)$ & $2(3)$ & $1(2)$ \\
\hline
\end{tabular}

Table 5 MR detected cartilage defects and marginal osteophytes of the TFF in 59 subjects

\begin{tabular}{llcl}
\hline & $\begin{array}{l}\text { Cartilage } \\
\text { defect }\end{array}$ & $\begin{array}{l}\text { No cartilage } \\
\text { defect }\end{array}$ & Total \\
\hline Marginal osteophyte & 27 & 4 & 31 \\
No marginal osteophyte & 8 & 20 & 28 \\
Total & 35 & 24 & 59 \\
\hline
\end{tabular}

Table 6 MR detected cartilage defects in and marginal osteophytes at the medial femoral condyle in 59 subjects

\begin{tabular}{llcc}
\hline & $\begin{array}{l}\text { Cartilage } \\
\text { defect }\end{array}$ & $\begin{array}{l}\text { No cartilage } \\
\text { defect }\end{array}$ & Total \\
\hline Marginal osteophyte & 11 & 1 & 12 \\
No marginal osteophyte & 14 & 33 & 47 \\
Total & 25 & 34 & 59 \\
\hline
\end{tabular}

corresponding MR images, which demonstrate a cartilage defect.

Meniscal abnormalities as full thickness tear and deformity (postoperative, post-traumatic, etc) ${ }^{13}$ were registered separately for the anterior, middle, and posterior portion of each meniscus. ${ }^{10}$ Figure 3 shows a posteroanterior radiogram with marginal osteophytes and the corresponding MR image, which demonstrates cartilage defects and a meniscal abnormality.

The MR studies were interpreted blind and separately by two of the authors (TB, OR) with experience in musculoskeletal MR imaging, who then reached a consensus.

The study was approved by the Committee on Ethics at the Faculty of Medicine, University of Lund.

STATISTICAL ANALYSES

The measure used to assess intraobserver and interobserver agreement was $\kappa$. A $\kappa$ value of $1.00-0.81$ was considered as very good, $0.80-0.61$ as good, $0.60-0.41$ as moderate, $0.40-0.21$ as fair, and $0.20-0.00$ as poor. ${ }^{14}$ The percentage concordance within and between observers was also calculated, as the distribu-

Table 7

(A) The correlation between MR detected cartilage defects and marginal osteophytes in the tibiofemoral joint with minimum joint space width $<3 \mathrm{~mm}$. Marginal osteophytes had a sensitivity of $93 \%$ and a positive predictive value of $93 \%$ for $M R$ detected cartilage defects

\begin{tabular}{|c|c|c|c|}
\hline & Cartilage defect & No cartilage defect & Total \\
\hline Marginal osteophyte & 14 & 1 & 15 \\
\hline No marginal osteophyte & 1 & 0 & 1 \\
\hline Total & 15 & 1 & 16 \\
\hline \multicolumn{4}{|c|}{$\begin{array}{l}\text { (B) The correlation between } M R \text { detected cartilage defects and marginal osteophytes in the tibiofemora } \\
\text { joint with minimum joint space width } \geqslant 3 \text { mm. Marginal osteophytes had a sensitivity of } 65 \%, \text { a } \\
\text { specificity of } 87 \% \text {, and a positive and negative predictive value of } 81 \% \text { and } 74 \% \text { respectively for } M R \\
\text { detected cartilage defects }\end{array}$} \\
\hline & Cartilage defect & No cartilage defect & Total \\
\hline Marginal osteophyte & 13 & 3 & 16 \\
\hline No marginal osteophyte & 7 & 20 & 27 \\
\hline Total & 20 & 23 & 43 \\
\hline
\end{tabular}

tion of grades of the marginal osteophytes was skewed.

The McNemar test was used to compare the number of osteophytes between the signal knee and the contralateral knee. The test was also performed with six contingency tables in which the number of marginal ostoephytes at the different aspects of the TFJ were compared with each other.

To analyse the relation between the MJS and the size of marginal osteophytes at medial femoral and the medial tibial condyle the Kruskal-Wallis test was used.

\section{Results}

Bilateral knee pain or pain in the contralateral knee only was reported by 17 people. In the remaining 42 patients the pain of the signal knee was unchanged or worse in 21 and was less or appeared only irregularly in 21 during the three years of observation.

Marginal osteophytes in the TFJ were registered in 31 of 59 of the signal and 24 of 59 of the contralateral knees. The number and grade of osteophytes in each location of the knees are shown in table $1(\mathrm{~A})$ and $1(\mathrm{~B})$. In 12 knees osteophytes of grade 2 or more were found. Osteophytes in the signal knee were more common at the medial tibial condyle $(p<0.001)$ and less common at the lateral femoral condyle $(p<0.05-p<0.001)$ than in any of the other condyles. In the medial and lateral $\mathrm{TF}$ compartment of the signal knees osteophytes were found in 30 and 14 cases respectively. More marginal osteophytes were found at the medial tibial condyle compared with the medial femoral condyle $(p<0.001)$ and at the lateral tibial condyle compared with the lateral femoral condyle $(p<0.01)$. These relations are listed in table $2(\mathrm{~A})$ and $2(\mathrm{~B})$. In the 42 people who had or had had pain in the signal knee only, more osteophytes were found in the medial tibial condyle $(p<0.05)$ of the signal knee compared with the contralateral knee. Table 3 shows the association between minimal joint space width and the grade of the medial tibial and the medial femoral osteophytes of the signal knees. The osteophytes increased in size with decreasing joint space width, at the medial femur $(p<0.001)$ and at the medial tibia $(\mathrm{p}<0.01)$.

The intraobserver variation of marginal and central osteophytes expressed as $\kappa$ values varied between $0.72-0.91$ and the percentage concordance within the observer was between $88-98 \%$. The interobserver variation of marginal and central osteophytes varied between and $0.49-0.88$. The percentage concordance between observers varied from 85 to $93 \%$.

In 35 of 59 of the TFJ MR detected cartilage defects were found. The most affected joint surface was the medial femoral where 25 knees $(\mathrm{p}<0.05)$ with cartilage defects were registered. ${ }^{10}$ Table 4 lists the number and grade of cartilage defects.

Table 5 shows a comparison between MR detected cartilage defects anywhere in the TFJ and marginal osteophytes. Marginal osteophytes had thus a sensitivity of $77 \%$, a specificity of $83 \%$, and a positive and a negative pre- 
Table 8 The sensitivity, the specificity and the positive and negative predictive value of radiographic tibiofemoral osteophytes for MR detected cartilage defects in the TFF. Data shown as percentages

\begin{tabular}{lcccccc}
\hline & $\begin{array}{c}\text { Medial } \\
\text { femur }\end{array}$ & $\begin{array}{l}\text { Medial } \\
\text { tibia }\end{array}$ & $\begin{array}{l}\text { Lateral } \\
\text { femur }\end{array}$ & $\begin{array}{l}\text { Lateral } \\
\text { tibia }\end{array}$ & $\begin{array}{l}\text { Tibial } \\
\text { spine }\end{array}$ & Intercondylar \\
\hline Sensitivity & 34 & 74 & 14 & 37 & 71 & 52 \\
Specificity & 100 & 83 & 100 & 96 & 58 & 75 \\
Positive predictive value & 100 & 87 & 100 & 93 & 71 & 74 \\
Negative predictive value & 51 & 69 & 44 & 51 & 58 & 53 \\
\hline
\end{tabular}

Table 9 Meniscal lesions and marginal osteophytes in the TFF in 59 subjects

\begin{tabular}{lccl}
\hline & Meniscal lesion & Meniscus intact & Total \\
\hline Osteophyte & 22 & 9 & 31 \\
No osteophyte & 9 & 19 & 28 \\
Total & 31 & 28 & 59 \\
\hline
\end{tabular}

dictive value of $87 \%$ and $71 \%$ respectively for MR detected cartilage defects. Table 6 shows a separate comparison between MR detected cartilage defects in the medial femoral condyle and marginal osteophytes at the same location. Marginal osteophytes at the medial femoral condyle had a specificity and a positive predictive value of $97 \%$ and $92 \%$ respectively for $M R$ detected cartilage defects in the same condyle while the sensitivity and negative predictive value was $44 \%$ and $72 \%$ respectively.

Table $7(\mathrm{~A})$ and $7(\mathrm{~B})$ show the correlation between marginal osteophytes and MR detected cartilage defects in knees with narrowing $(<3 \mathrm{~mm})$ and non-narrowing $(\geqslant 3 \mathrm{~mm})$. For MR detected cartilage defects anywhere in the TFJ the sensitivity, the specificity, and the positive and negative predictive values for marginal and central osteophytes at each position were calculated (table 8).

Meniscal abnormalities on MR imaging were found in 31 of 59 knees. ${ }^{10}$ The medial meniscus was abnormal in 30 knees and the lateral meniscus in 10 knees. Table 9 shows a comparison between the presence of meniscal abnormalities and marginal osteophytes anywhere in the TFJ. Marginal osteophytes had thus a sensitivity of $71 \%$, a specificity of $68 \%$, and a postive and negative predictive value of $71 \%$ and $68 \%$ respectively for meniscal abnormalities. For meniscal abnormalities anywhere in the TFJ the sensitivity, the specificity, and the positive and negative predictive values for marginal and central osteophytes at each position were calculated (table 10).

\section{Discussion}

$\mathrm{OA}$ is a multifactorial disease with a focal loss of articular cartilage with variable underlying bone reaction. ${ }^{15}$ These lesions have a varying relation to radiographic findings (osteophytes, joint space narrowing, bone loss, subchondral sclerosis, and subchondral cysts) and to clinical

Table 10 The sensitivity, the specificity and the positive and negative predictive value of radiographic tibiofemoral osteophytes for major meniscal abnormalities in the TFF. Data shown as percentages

\begin{tabular}{lllllll}
\hline & $\begin{array}{l}\text { Medial } \\
\text { femur }\end{array}$ & $\begin{array}{l}\text { Medial } \\
\text { tibia }\end{array}$ & $\begin{array}{l}\text { Lateral } \\
\text { femur }\end{array}$ & $\begin{array}{l}\text { Lateral } \\
\text { tibia }\end{array}$ & $\begin{array}{l}\text { Tibial } \\
\text { spine }\end{array}$ & Intercondylar \\
\hline Sensitivity & 39 & 73 & 16 & 39 & 52 & 63 \\
Specificity & 96 & 72 & 100 & 93 & 71 & 46 \\
Positive predictive value & 92 & 73 & 100 & 86 & 65 & 56 \\
Negative predictive value & 59 & 72 & 52 & 58 & 59 & 54 \\
\hline
\end{tabular}

symptoms (articular pain and loss of function). In practice the definition of OA rests upon clinical and radiographic evaluation.

Marginal osteophytes arise in the synovium overlying bone at the junctional zone and is the result of metaplasia of the synovium into cartilage. ${ }^{16} 17$ "Vascularization of the subchondral bone marrow in this region produces calcification of the adjacent cartilage and stimulates endochondral ossification. The developing outgrowth extends into the "free" articular space, along the path of least resistance. Generally, it contains spongy trabeculae and fatty marrow and is covered with articular cartilage". ${ }^{18}$

Ahlbäck ${ }^{1}$ found that marginal osteophytes were larger when the joint space was obliterated, than in joints with narrowing This difference existed in both the medial and the lateral TF compartments and the prevalence of osteophytes increased with increasing narrowing. Danielsson $e t a l^{19}$ found that osteophytes in the TFJ were not a definite sign that structural changes later will develop. Hernborg et $a l^{20}$ stated that osteophytes in the TFJ are probably most of all related to age and are not necessarily an early sign of OA but osteophytes are frequently observed in cases who develop OA later on, defined as structural changes in the form of subchondral sclerosis and cysts.

MR imaging is considered to be an accurate means for detecting and staging moderate and advanced cartilage lesions in the knee joint ${ }^{8}$ and is thus useful in the evaluation of knee OA. The fast spin echo $2 \mathrm{D}$ sequence used in this study does not differ in this respect and has also been used by others. ${ }^{21}{ }^{22}$ The reason why we did not pursue with the 3D gradient echo (Dess) was that reconstruction in coronal and axial planes were of inferior quality to evaluate hyaline cartilage. The examination time was considerably longer than the tSEPdT2 sequence, which gives an increased risk of motion artefacts. The examination quality of the MR studies for the first seven patients was considered equal and they have therefore been included in the study. According to recent results it appears as if high resolution 3D gradient echo sequences with the addition of fat suppression or magnetisation transfer contrast are the best for depicting hyaline cartilage. $^{23-25}$ As mentioned above the 3D gradient echo sequences have a long acquisition time with potential disadvantages. Meniscal abnormalities are mainly assessed by the Pd weighted images of the conventional SEPdT2 sequence. There have been doubts about the accuracy of diagnosing these abnormalities with turbo SEPdT2 sequence but this technique performs similar to the conventional spin-echo sequence, ${ }^{26-28}$ which is also in agreement with our clinical experience.

This study was performed in middle aged people with comparatively mild OA, as only 16 of 59 had joint space narrowing $(<3 \mathrm{~mm})$, the medial compartment most commonly being affected, 15 of $16 .^{10}$ The specificity and positive predictive value of marginal osteophytes of the TFJ were surprisingly high for MR detected cartilage defects anywhere in the joint. In the 
group of patients studied joint space narrowing $(<3 \mathrm{~mm})$ has been found to have a very high specificity $(96 \%)$ and positive predictive value (94\%) for MR detected cartilage defects while the sensitivity was low, less than $50 \% .{ }^{10}$ In this study the presence of marginal osteophytes had a specificity and positive predictive value for MR detected cartilage defect, which was almost as high, both in knees with narrowing and in knees with non-narrowing. Furthermore the sensitivity was considerably higher.

We have also found that a marginal osteophyte at the medial tibial aspect has a positive predictive value of $87 \%$ (26 of 30 ) for a MR detected cartilage defect in the signal knee and if an additional osteophyte at the lateral femoral condyle or at the lateral tibial condyle was found the predictive value increased to $100 \%$ and to almost $100 \%$ if this additional osteophyte was localised to the medial femoral condyle. These findings emphasise further the significance of marginal osteophytes in the TFJ as a sign of MR detected cartilage defects in the same joint.

It has to be pointed out that the radiographic technique used underestimates the presence of marginal osteophytes, as it is impossible to evaluate the total joint margin of each condyle. In addition MR imaging is less sensitive than athroscopy in identifying especially superficial cartilage defects. ${ }^{22}$ No strong association was found between central osteophytes and MR detected cartilage defects.

In the medial TF compartment the finding of a marginal osteophyte at the femoral condyle has a high specificity but low sensitivity for a MR detected cartilage defect in the same condyle while the specificity is almost the same but sensitivity considerably higher of marginal osteophytes at the tibial condyle. The reason for the great difference in sensitivity is not clear. MR detected cartilage defects were registered in 25 medial femoral and in 12 medial tibial condyles, while the distribution of marginal osteophytes is the reverse, with the presence of 12 osteophytes at the medial femoral condyle and 30 at the medial tibial condyle. This raises the question that the aetiology for the development of marginal osteophytes at the medial femoral condyle and at the medial tibial condyle is not the same. Perhaps the presence of medial meniscus pathology plays a part in the development of marginal osteophytes at the medial tibial condyle. Two findings support this theory. A major abnormality was registered in 30 of 59 medial menisci and in the medial TF compartment a marginal osteophyte at the femoral condyle was found in combination with an osteophyte at the tibial condyle only. A correspondent relation between marginal osteophytes was found in the lateral TF compartment.

The strong association between marginal osteophytes and MR detected cartilage defects is confirmed by studies on experimentally induced knee OA in dogs, in which osteophytes appear early in the course of the disease, being detectable within two weeks of surgery. ${ }^{17}{ }^{29}$ Our results does not necessarily contradict the findings by Danielsson et $a l^{19}$ and Hernborg et al..$^{20}$
The OA process can probably remain static in some people or even reverse. In others the progression is slow and in yet another group of people with OA the progress is rapid. ${ }^{30}$ In our study the marginal osteophytes increased in size with decreasing minimal joint space width. This has also been found by others. ${ }^{3}{ }^{31}$

We found no relation between central osteophytes and MR detected cartilage lesions in the TFJ. There was even a tendency of more central osteophytes (NS) in the contralateral knee than in the signal knee and these osteophytes are probably not a reliable sign of early OA. For osteophytes at the tibial spine this is in agreement with a study by Donelly et $a l^{32}$ but not with Reiff $e t a l .^{33}$

The number of osteophytes in the contralateral knee was generally smaller and the difference was statistically significant $(p<0.05)$ at the medial tibial condyle only. This finding is in agreement with a previous study. ${ }^{4}$

The intraobserver and interobserver variation for classifying marginal osteophytes was in general good or very good and never below 0.49 and this has also been found by others. ${ }^{54}$ However, the distribution of grades of osteophytes was skewed and under these circumstances the $\kappa$ value tends to be low even if the percentage concordance between the gradings is high as in our study.

In general the specificity and the positive predictive value of marginal tibiofemoral osteophytes for meniscal abnormalities anywhere in the TFJ was high and especially at the medial and the lateral femoral condyles. In an earlier study we found that a meniscal abnormality had a high specificity for joint space narrowing $(<3 \mathrm{~mm})$ in the same compartment. ${ }^{1035}$

In the group studied the presence of marginal osteophytes in the TFJ thus reveals more knees (27 of 31) with MR detected cartilage defects than joint space narrowing (15 of $16)^{10}$ and this with almost the same high specificity in middle aged people with chronic knee pain. If these findings are generalised the presence of marginal osteophytes is useful and important in diagnosing knee OA for both clinical and epidemiological purposes. The grading scale introduced by Kellgren and Lawrence ${ }^{1}$ seems to be relevant in early OA of the TFJ if central osteophytes are not taken into consideration.

To estimate the severity of the OA process MR imaging is the most sensitive non-invasive procedure but because of high costs is not suitable for routine use. Thus, at least for the near future, the interpretation of joint space narrowing in standard posteroanterior weightbearing knee radiograms in semiflexion will be the best method to grade the severity of tibiofemoral OA.

This study was supported by grants from the Thelma Zoégas Foundation, the Stig och Ragna Gorthon Foundation and Reumatikerförbundet. We are grateful to Göran Ejlertsson for statistical assistance.

1 Kellgren JH, Lawrence JS. Radiological assessment of osteo-arthrosis. Ann Rheum Dis 1957;16:494-501. 2 Kellgren JH, Jeffrey MR, Ball J. The epidemiology of chronic
rheumatism: atlas of standard radiographs of arthritis. Vol 2 . rheumatism: atlas of standard radiograph 
3 Ahlbäck S. Osteoarthrosis of the knee. A radiographic investigation. Acta Radiol 1968;277(suppl):7-72.

4 Spector TD, Hart DJ, Byrne J, Harris PA, Dacre JE, Doyle DV. Definition of osteoarthritis of the knee for epidemiological studies. Ann Rheum Dis 1993;52:790-4.

5 Cicuttini FM, Baker J, Hart DJ, Spector TD. Association of pain with radiological changes in different compartments and views of the knee joint. Osteoarthritis Cartilage 1996; $4: 143-7$

6 Cicuttini FM, Baker J, Hart DJ, Spector TD. Choosing the best method for radiological assessment of patellofemoral osteoarthritis. Ann Rheum Dis 1996;55:134-6.

7 Hart DJ, Spector TD. The classification and assessment of osteoarthritis. In: Silman A J, Symmons DPM, eds. Classification and assessment of rheumatic diseases. Part I. Baillieres Clin Rheumatol 1995;9:407-32.

8 Peterfy C. MR imaging. In: Bird HA, Dougados M, eds. Imaging techniques. Part II: Modern methods. Baillieres Imaging techniques. Part II: Moder

9 Petersson IF, Boegård T, Saxne T, Silman A J, Svensson B. Radiographic osteoarthritis of the knee classified by the Radiographic osteoarthritis of the knee classified by the Ahlbäck and Kellgren and Lawrence systems for the tibiofemoral joint in people aged 35-54 years

10 Boegård T, Rudling $\mathrm{O}$, Petersson IF, Sanfridsson J, Saxne T, Svensson B, et al. Postero-anterior radiogram of the knee in weight-bearing and semiflexion: comparison with MR imaging. Acta Radiol 1997;38:1063-70.

11 Altman RD, Hochberg M, Murphy WA Jr, Wolfe F, Lequesne $M$. Atlas of individual radiographic features in osteoarthritis. Osteoarthritis Cartilage 1995;3 (suppl A):3 70.

12 Buckland-Wright C. Protocols for precise radio-anatomical positioning of the tibiofemoral and patellofemoral compartments of the knee. Osteoarthritis Cartilage 1995;3 (suppl A):71-80.

13 Crues JV III, Stoller DW. The menisci. In: Mink JH, Reicher MA, Crues IV III, Deutsch AL, eds. Magnetic resonance imaging of the knee. 2nd ed. New York: Raven Press, 1992: imaging

14 Altman DG. Practical statistics for medical research. London: Chapman and Hall, 1991.

15 Dieppe PA. Osteoarthritis-Introduction. In: Klippel JH, Dieppe PA, eds. Rheumatology. 1st ed. London: Mosby, 1994:7.2.1

16 Marshall JL. Periarticular osteophytes. Initiation and formation in the knee of the dog. Clin Orthop 1969;62:3747.

17 Gilbertson EMM. Development of periarticular osteophytes in experimentally induced osteoarthritis in the dog. Ann Rheum Dis 1975;34:12-24

18 Resnick D. Niwayama G. Degenerative disease of extraspinal locations. In: Resnick D, ed. Diagnosis of bone and joint disorders. 3rd ed. Philadelphia: W B Saunders, 1995: 1263371.

19 Danielsson L, Hernborg J. Clinical and roentgenologic study of the knee joints with osteophytes. Clin Orthop 1970;69:302-12.
20 Hernborg J, Nilsson BE. The relationship between osteophytes in the knee joint, osteoarthritis and aging. Acta phytes in the knee joint, osteoa

21 Tervonen O, Dietz MJ, Carmichael SW, Ehman RL. MR imaging of knee hyaline cartilage: evaluation of two- and three-dimensional sequences. J Magn Reson Imaging 1993;3:663-8

22 Broderick LS, Turner DA, Renfrew DL, Schnitzer TJ, Huff JP, Harris C. Severity of articular cartilage abnormality in patients with osteoarthritis: evaluation with fast spin-echo MR vs arthroscopy. AJR 1994;162:99-103.

23 Peterfy CG, van Dijke CF, Janzen DL, Glüer CC, Namba R, Majumdar S, et al. Quantification of articular cartilage in the knee with pulsed saturation transfer subtraction and fat-suppressed MR imaging: optimization and validation. Radiology 1994;192:485-91.

24 Recht MP, Pirraino DW, Paletta GA, Schils JP, Belhbek GH Accuracy of fat-suppressed three-dimensional spoiled gradient-echo MR imaging in the detection of patellofemogradient-echo MR imaging in the detection of patellofemo-
ral articular cartilage abnormalities. Radiology 1996;1 98:209-12.

25 Disler DG. Fat-suppressed three-dimensional spoiled gradient-recalled MR imaging: assessment of articular and
physeal hyaline cartilage. AJR 1997;169:1117-23.

26 Fellner C, Geissler A, Held P, Strotzer M, Treibel W, Fellner F. Signal, contrast, and resolution in optimized Pd- and T2-weighted turbo SE images of the knee. J Comput Assist Tomogr 1995; 19:96-105.

27 Escobedo EM, Hunter JC, Zink-Brody GZ, Wilson AJ, Harrison SD, Fisher DJ. Usefulness of turbo spin-echo MR imaging in the evaluation of meniscal tears: comparison with a conventional spin-echo sequence. AJR 1996;167: 1223-7.

28 Chueng LP, Li KCP, Hollett MD, Bergman AG, Herfkens RJ. Meniscal tears of the knee: accuracy of detection with fast spin-echo MR imaging and arthroscopic correlation in 293 patients. Radiology 1997;203:508-12.

29 McDevitt C, Gilbertson E, Muir H. An experimental model of osteoarthritis; early morphological and biochemical of osteoarthritis; early morphological and
changes. J Bone Joint Surg Br 1977;59:24-35.

30 Alexander C. Osteoarthritis: a review of old myths and current concepts. Skeletal Radiol 1990;19:327-33.

31 Buckland-Wright JC, Macfarlane DG, Jasani MK, Lynch JA. Quantitative microfocal radiographic assessment of osteoarthritis of the knee from weight bearing tunnel and semiflexed standing views. J Rheumatol 1994;21:1734-41.

32 Donnelly S, Hart DJ, Doyle DV, Spector TD. Spiking of the tbial tubercles - a radiological feature of osteoarthritis? Ann Rheum Dis 1996;55:105-8.

33 Reiff DB, Heron CW, Stoker DJ. Spiking of the tubercles of the intercondylar eminence of the tibial plateau in osteoarthritis. Br J Radiol 1991;64:915-17.

34 Cooper C, Cushnaghan J, Kirwan JR, Dieppe PA, Rogers J, McAlindon $\mathrm{T}$, et al Radiographic assessment of the knee joint in osteoarthritis. Ann Rheum Dis 1992;51:80-2.

35 Boegård $\mathrm{T}$, Petersson IF, Jonsson K. Tibiofemoral joint space narrowing and meniscal lesions. [Letter]. Br J Rheumatol 1997;36:1236. 